Article

\title{
Benchmarking Sustainable Manufacturing: A DEA-Based Method and Application
}

\author{
Jun-Der Leu, Wen-Hsien Tsai *, Mei-Niang Fan and Sophia Chuang \\ Department of Business Administration, National Central University, Taoyuan City 32001, Taiwan; \\ leujunder@mgt.ncu.edu.tw (J.-D.L.); vivian.fan.vf1@gmail.com (M.-N.F.); Sophia6078@gmail.com (S.C.) \\ * Correspondence: whtsai@mgt.ncu.edu.tw
}

Received: 16 October 2020; Accepted: 12 November 2020; Published: 15 November 2020

\begin{abstract}
In past decades, many manufacturing enterprises have followed the business model of productivity maximization, in which achieving maximum profit using limited resources is the business goal. Although this industrial strategy may make profit, it can be detrimental to the long-term social welfare. Industrial regulations require that enterprise should be responsible for the natural environment and the health of their employees while achieving their business goals. This presents a complex problem involving the trade-off between ecology and economy so that an efficient strategic decision support method is needed. Since the value-added process of a manufacturing company encompasses both desirable and undesirable outputs, in this study we use a data envelopment analysis-based model to measure performance sustainability. In it, energy, water, and manpower are considered as input resources, meanwhile $\mathrm{CO}_{2}$ emissions, wasted water, chemical compounds, and laborers' injuries are considered as bad outputs. The proposed approach is applied to a global chemical manufacturing company to benchmark the sustainability of its production sites located in Asia. Based on the benchmarking results, the theoretical and practical implications are discussed.
\end{abstract}

Keywords: sustainable manufacturing; data envelopment analysis (DEA); bad-output model

\section{Introduction}

Sustainability is a challenge for global manufacturing industries, since the processes that generate profits often damage natural resources as well as the environment. To remain sustainable, companies must revisit the traditional business model by considering the effect of profit-making on the planet's resources and on society at the same time [1]. It is a requirement for the start-up operations in the intense of manufacturing competition in the industry to meet or exceed local regulation [2]. On the other hand, increasingly stringent regulations, community, and customer pressure require companies to incorporate the full scope of sustainability operations into their business goals efficiently and so as to increase their competitive advantage [3]. Companies must also develop long term sustainability strategy and investment facilities to reduce their environmental impact and protect employees and public health. Thus, leveraging economic profits and ecological sustainability becomes an issue.

Public regulations also present challenges. Restrictions on the use of certain hazardous substances in electronic equipment (Restriction of Hazardous Substances) mean that such products cannot be sold within the European Union (EU) [4]. The EU also implemented its Registration, Evaluation, Authorization, and Restriction of Chemical Substances (REACH) regulations to protect human health and the environment [5]. The regulations of the United States Environmental Protection Agency, in Section 40 of the U.S. Code of Federal Regulations, define the emission limitations for the protection of people and the environment [6]. These stringent regulations oblige the chemical industry to comply, so substantial effort is required to prevent detrimental effects on business operations. The public, the company, and the government must comply with the regulations, without any concessions. These regulations thus impose 
a requirement on companies to be responsible for protecting public health and the environment [7]. The regulation, international standard and stakeholders' communications are the factors for taking CSR initiatives in considering of company reputation not only financial performance [8]. Regulation is the bottom line that a responsible local or global company must comply with for sustainable operating and maintain long-term trust relationship in community. A manufacturing company should also consider the potential business benefits of environmental regulations.

A global firm faces competition to enhance their capability and increase value-added practices for sustainable manufacturing for globalization [9]. Sustainable manufacturing is one of the key company strategies toward long term business operations that require process and management system for implementation. Kishawy et al. (2018) develops an approach that is comprised of three levels of product, process, and system for assessment and implementation to build up sustainable manufacturing systems [10]. A firm selects proper sustainable manufacturing practices for implementation to improve manufacturing performance not only a single element [11]. An efficient decision-support tool is necessary for companies to measure and manage the sustainability of their production sites worldwide.

Data envelopment analysis (DEA) is a mathematical programming approach used to measure productive efficiency, based on the idea of the production frontier in micro-economics. The two basic radial-DEA models, introduced by Charnes, Cooper, and Rhodes (CCR) and Banker, Charnes, and Cooper (BCC), define the input excess and output shortfall as inefficiencies. Zhou et al. (2008a) surveyed the application of DEA in 100 energy and environment studies and found that efficiency could be effectively measured using the radial methods of the CCR and BCC models [12]. The value-added process of manufacturing companies encompasses both desirable and undesirable outputs. We therefore used the DEA bad-output model to evaluate the sustainability performance of a manufacturing company, in which input and bad-output factors, the natural environment, and laborers' health, and safety were included. In addition to the theoretical model, this study presents an application for a global chemical manufacturing company to implement sustainability benchmarking in its production factories.

This paper is organized as follows: The related researches are reviewed in the Section 2, and the Section 3 states the research method. In Section 4, we demonstrate the application case, and the research finding in terms of practical application and theoretical implications are presented in the Section 5. Conclusions and future research are presented in Section 6.

\section{Literature Review}

Sustainable development can be viewed as satisfying the needs of the current generation without compromising the ability to meet the needs of future generations [13]. Sustainable development consists of environmental, societal, and economic domains, also known as the "triple bottom line" [14]. The extremely climate, temperature and civilization caused the natural resources shortage that activates the design for natural that is friendly to environment and people [15]. A sustainable long-term strategy involves both operational performance and environmental protection, so that ecological and natural resources can continue to be used [16]. The aim of the operational framework of sustainable development is to minimize the effect of company operations on people and the environment, and to ensure that the interests of internal and external stakeholders are not sacrificed in the interests of profit [17]. Significant advantages can be gained from implementing sustainability, as company performance can be improved in safety, health, and environmental matters, and also in terms of efficiency and productivity. The sustainability related topics summarized in Table 1 and description as follows: 
Table 1. Sustainability related topics.

\begin{tabular}{|c|c|c|c|}
\hline Perspectives & Authors & Approach & Process \\
\hline \multirow{4}{*}{ Life-cycle assessment } & [18] & Sensitivity analysis & Electric vs. combustion engine cars \\
\hline & [19] & Industrial symbiosis (IS) & $\begin{array}{l}\text { Small and medium enterprise } \\
\text { (SMEs) tannery }\end{array}$ \\
\hline & [20] & $\begin{array}{c}\text { Multi-objective, mixed-integer } \\
\text { nonlinear programing model }\end{array}$ & Hydrocarbon biofuels \\
\hline & [21] & Environmental Impact Assessment & $\begin{array}{l}\text { Landfills, biological treatments, } \\
\text { and paper recycling. }\end{array}$ \\
\hline \multirow{4}{*}{ Lean and green practices } & [22] & PLS-SEM & Manufacturing \\
\hline & [23] & Design of Experiment & $\begin{array}{l}\text { Manufacturing and waste } \\
\text { treatment process }\end{array}$ \\
\hline & [24] & Lean six sigma tools & Manufacturing processes \\
\hline & [25] & $\begin{array}{l}\text { lean manufacturing tools and } \\
\text { value-stream mapping }\end{array}$ & Manual handling process \\
\hline \multirow{3}{*}{ Resource-based views } & [26] & Multiple regressions & $\begin{array}{l}\text { Production operations in global } \\
\text { supply chains }\end{array}$ \\
\hline & [27] & Cross-sectional survey & Manufacturing plants \\
\hline & [28] & SEM & Maintenance facilities \\
\hline \multirow{3}{*}{ Reversed logistics } & [29] & $\begin{array}{l}\text { Mathematical model of the reverse } \\
\text { logistics social responsibility }\end{array}$ & Supply chains \\
\hline & [30] & Management information system & Customers and suppliers \\
\hline & [31] & Content analysis & Supply chains \\
\hline \multirow{3}{*}{ Eco-design product } & [32] & Content analysis & $\begin{array}{c}\text { ICT (Information and communication } \\
\text { technology) sectors }\end{array}$ \\
\hline & [33] & New eco-design tools & $\begin{array}{l}\text { Manufacturing, transportation, } \\
\text { and users }\end{array}$ \\
\hline & [34] & Multi-criteria decision support & Furniture companies. \\
\hline \multirow{3}{*}{ Benchmarking } & [35] & $\begin{array}{l}\text { Lean, Six Sigma and life } \\
\text { cycle assessment }\end{array}$ & Construction \\
\hline & [36] & $\begin{array}{c}\text { Benchmarking of } \\
\text { sustainability method }\end{array}$ & Electrnoics \\
\hline & [37] & Two-Stage DEA model & Tourism Service \\
\hline
\end{tabular}

\section{- Life-cycle assessment}

Helmers et al. (2020) conducted the environmental impact assessment on vehicles using different fuels through Life-cycle assessment [18]. Daddi et al. (2017) used a tool of life-cycle assessment by implementing the approach of industrial symbiosis (IS) to collaborative and sharing environmental initiatives and solutions in the small and medium enterprises (SMEs) tannery industry for continuous improvement [19]. Wang et al. (2013) proposed a multi-objective, mixed-integer, nonlinear programing model to evaluate environmental effects by assessing the life-cycle of hydrocarbon biofuels. Greenhouse gases and carbon dioxide accounted for $90 \%$ of the environmental effects of processes and transportation, which can be further reduced [20]. Koroneos and Nanaki (2012) applied life-cycle assessment to sustainable decision making in the waste management of paper, food waste, plastics, leather, wood, glass, and metals including aluminum, using the inputs of resources and energy and the outputs of emissions, energy, and bio-products. They found that different energy levels of electrical sources affected the results of the waste treatment methods of landfills, biological treatments, and paper recycling [21].

\section{- “Lean and green" practices}

Green et al. (2019) concluded that implementation green supply chain programs of JIT and TQM can reduce waste, cost, delivery and increase customers' service level and satisfaction [22]. Fercoq et al. (2016) 
consolidate lean and green approaches using a tool of design of experiment (DOE) to identify the two factors of lean and waste to reduce, reuse and recover the potential waste generation volume in the manufacturing and waste treatment process to improve solid waste performance in environmental aspects [23]. Li et al. (2013) proposed a management model to develop a manufacturing strategy that applied the Bayesian network approach, originating from lean six sigma tools, to prioritize the improvement of manufacturing processes and gain competitive advantage in the industry [24]. Acharya (2011) applied lean manufacturing tools and value-stream mapping to improve processes for manual handling, thereby eliminating non-value-added waste. This method can contribute to operational efficiency in terms of cost reductions and output gains by conserving human resources, materials, spaces, advantages, and cycle times [25].

\section{- $\quad$ Resource-based views}

Koh et al. (2016) developed an integrated resource efficiency view (IREV) to utilize and measure natural resources' efficiency to contribute the performance sustainability and corporate social responsibility [26]. Gavronski et al. (2011) applied the resource-based view (RBV) to conduct a survey and develop green manufacturing capability with plant resources through top management commitment, knowledge exchange in organizational learning, and environmental investment. Their goal was to support green supply chain management and to enable the development of a green manufacturing capability and sustained competitive advantage [27]. Aragón-Correa et al. (2008) conducted a survey focusing on the natural environmental strategy of small- and medium-sized enterprises (SMEs) using the RBV approach. They developed an environmental practice based on the organizational potential of a shared vision, stakeholder management, and strategic proactivity, which can create positive and proactive relationships between eco-efficient practices, environmental practices, and company performance [28].

\section{- $\quad$ Reversed logistics}

Sudarto et al. (2017) developed a mathematical model of the reverse logistics social responsibility in the supply chains in order to react to the uncertainty of product life cycle to optimize a sustainability performance [29]. García-Rodríguez et al. (2013) conducted a case study in which raw materials for the handmade sector were acquired through reverse logistics to sustain the products' long lifecycle. They addressed uncertain supply of end-of-life products by implementing a management information system to communicate with customers and to regard them as suppliers. The communication loop was thus improved, and customers and suppliers were in turn persuaded to improve the management of resources and to reuse, repair, and recycle to improve efficiency [30]. Jayant et al. (2012) conducted a content analysis of more than 100 papers to identify the reverse factors of environmental aspects that could be integrated into the sustainable supply chain to achieve economic goals. The surveyed methods included linear, non-linear, and mixed-integer nonlinear programming, and network equilibrium, stochastic, and simulation models [31].

\section{- Eco-design product}

Sinvonen and Partanen (2017) applied a content analysis approach to the ICT (information and communication technology) sectors that they consider for eco-design at the beginning phase to extend the durability from the point of view of life-cycle assessment, which has a positive result on environmental performance [32]. Casamayor and Su (2013) applied new eco-design tools to lighting products to reduce the environmental impact from. The highest impact phase was found to be transportation, followed by the user and manufacturing phases, and the tools were used for prescription, database, and analytical purposes [33]. Borchard et al. (2012) proposed a multi-criteria decision support method, weighted by an analytic hierarchy process to evaluate the eco-design constructs of furniture companies. This flexible method enabled companies to identify the priorities of each eco-design construct and make emergency changes according to the environmental requirements [34]. 


\section{- Benchmarking}

Tasdemir et al. (2020) developed a framework for benchmarking the sustainable performance by Lean, Six Sigma, and life cycle assessment to identify improvement opportunities of construction industry [35]. da Costa et al. (2020) identified sustainability indicators for benchmarking the performance and reduce the environmental impact of product life cycle for electronics industry through benchmarking of sustainability method [36]. Radovanov et al. (2020) conducted a two-stage DEA model for benchmarking the sustainability performance of Tourism service for driving improvement and tourism development [37].

Most studies have investigated the relationship of sustainability to energy, environmental, and economic factors, focusing less on the social factors affecting safety performance [38,39]. Chodakowska and Nazarko (2020) conducted a DEA literature review of 30 papers in the EU countries and integrate hard and soft data to proposed hybrid models [40]. Companies may assess safety performance using factors such as measures of training or the external certification of occupational health and safety. Examples include OHSAS18001 certification and implementation [41]; Health, Safety, and Environment (HSE) training man-hours; the number of HSE personnel; the budget allocated to HSE resources; and the inclusion of HSE factors in employees' objectives and performance evaluations [42]. Employees are core assets working in company to caring their safety and health that can foster safety culture and increase their working satisfaction and morale. So that can trigger the financial and operational performance for sustainable operation. True sustainability performance measurement requires the consideration of all aspects related to social actors on safety and health. Therefore, the application case was focusing on two dimensions-social and environmental of triple bottom line. The input and output variables described on Section 4.

\section{Method}

Data envelopment analysis (DEA) is a non-parameter application method for evaluating efficiency and has been widely applied to operational research and management [43]. The core concept is that productivity, from output to input, is derived from economic factors [44]. Environmental evaluation requires the identification of desirable and undesirable output [45]. Zhou et al. (2008a) identified five efficiency measurements from over 100 energy and environmental research papers: (1) a radial efficiency measure, (2) a non-radial efficiency measure, (3) a slacks-based efficiency measure, (4) a hyperbolic efficiency measure, and (5) a directional distance-function efficiency measure [12]. The slacks-based efficiency measure has the highest discrimination power of the five. The monotone property of slacks-based efficiency decreases the excess inputs and bad outputs simultaneously for every slack. SBM was thus applied to undesirable outputs as part of our research methodology for evaluating sustainability performance [46].

Assume there are $\mathrm{n}$ decision-making units (DMUs). Each DMU has three factors: inputs, good outputs, and bad (undesirable) outputs, which are represented by three vectors: $x \in R^{m}, y^{g} \in R^{S 1}$, and $y^{b} \in R^{S 2}$, respectively. The definition of the matrices is from Equations (1)-(9) [46].

$$
\begin{aligned}
X & =\left[\chi_{1}, \ldots, \chi_{n}\right] \epsilon R^{m X n} \\
Y^{g} & =\left[Y_{1}^{g}, \ldots, Y_{n}^{g}\right] \epsilon R^{s_{1} X n} \\
Y^{b} & =\left[Y_{1}^{b}, \ldots, Y_{n}^{b}\right] \epsilon R^{s_{2} X n}
\end{aligned}
$$

The possibility set $(P)$ can be defined as

$$
P=\left\{\left(\chi, y^{g}, y^{b}\right) \mid \chi \geq X \lambda, y^{g} \leq Y^{g} \lambda, y^{b} \geq Y^{b} \lambda, \lambda \geq 0\right\}
$$


The slacks-based measure (SBM) undesirable model can be represented as

$$
\rho^{*}=\min \frac{1-\frac{1}{m} \sum_{i=1}^{m} \frac{s_{i}^{-}}{\chi_{i 0}}}{1+\frac{1}{s_{1}+s_{2}}\left(\sum_{r=1}^{s_{1}} \frac{s_{r}^{g}}{y_{r 0}^{g}}+\sum_{r=1}^{s_{2}} \frac{s_{r}^{b}}{y_{r 0}^{b}}\right)}
$$

subject to

$$
\begin{gathered}
\chi_{0}=X \lambda+s^{-} \\
y_{0}^{g}=Y^{g} \lambda-s^{g} \\
y_{0}^{b}=Y^{b} \lambda+s^{b} \\
s^{-} \geq 0, s^{g} \geq 0, s^{b} \geq 0, \lambda \geq 0
\end{gathered}
$$

where $s^{g} \in R^{S 1}$ represents shortages in good outputs, and the vectors $s^{-} \in R^{m}$ and $s^{b} \in R^{S 2}$ represent excesses in inputs and bad outputs, respectively. Equation (5) demonstrates that to satisfy the objective value $0<\rho^{*} \leq 1$, it is necessary to increase $s^{g}$ and reduce $s^{b}$ and $s^{-} \cdot \rho^{*}=1$ represents the objective, projected along the efficient frontier for the bad (undesirable) output model.

\section{Application Case}

\subsection{Case Company}

The case company was a leading global manufacturer of paints and coatings, operating in over 80 countries in North America, Europe, Asia, and Latin America. The headquarters, located in the Netherlands, employed over 55,000 staff at the end of 2020. Its long-term financial business goals were increased revenue, profit, and working capital, and its non-financial goals were safety, ecology efficiency, and diversity. The business structure, in which the business unit Decorative Paints makes $33.93 \%$ of global sales, Performance Coating 32.69\%, and Specialty Chemicals 33.76\%. The proposed sustainability method was first applied to the Decorative Paints factories in Asia.

The Decorative Paints unit included interior, exterior, and protective products. The company's marketing and business strategy was aimed at driving growth, while its innovation was driven by environmental and health legislative and regulatory pressure. The company developed eco-premium products such as heat-reflective exterior paints with energy-saving benefits, paints including fewer volatile organic compounds (VOCs) with the benefits of durability and wash ability, and water-based products. The percentage of revenue from these products for 2018, 2019, and 2020 was $15 \%, 22 \%$, and $29 \%$, respectively. Essential raw materials were resin or binders, titanium dioxide, and packaging materials. Titanium dioxide had the highest cost, as it was a scarce natural resource.

\subsection{Model Setup}

Rapid technology development and high pressure for keeping the competitive advantage, so some companies adopt benchmarking to improve productivity [47]. Benchmarking is one of the features of total quality management (TQM) for sustaining the competitive advantage [48]. The benchmarking has been applied on theoretical and practical for a company to improve organization performance and competitive advantage [49]. Cook et al. (2014) measured the efficiency of every DMU on production frontier for application DEA method for performance evaluation and benchmarking toward achieving best practice [50]. Therefore, it is important concept for applying DEA model for benchmarking to learn on new techniques and knowledge for sharing the good practice for driving continuous improvement in organization.

Benchmarking has been introduced and implemented on various industries by using DEA methods. Such as Wang et al. (2018) developed a DEA-Tobit model for benchmarking water resource usage efficiency for 30 provinces in China [51]. Novickyte and Droždz (2018) measured 
the banking sector's efficiency in Lithuanian by DEA input oriented CRS and VRS DEA model [52]. Mazumder et al. (2018) develop ANP and benchmark the manufacturing organization by proposing DEA input oriented CRS for productivity improvement [53]. Wang et al. (2018) selected suitable and qualified supplier by using Fuzzy ANP and DEA CCR, BCC, and SBM model for benchmarking [54]. Lin et al. (2018) developed a new hybrid model of AHP and two-stage additive network DEA for sustainability improvement in Taiwan semiconductor manufacturing sector [55].

The data key in a HSE system from 16 sites in Asia of the case company that required applying the same sustainability index. Sixteen sites-three were located in China, five in India, two in Vietnam, and one each in Indonesia, Thailand, Taiwan, Malaysia, Singapore, and Papua New Guinea. Quarterly data from 2018 to the first half of 2020 were used. Site HSE team submitted sustainable reporting that validated by regional data management team for any data variant that supply chain head and Corporate HSE to validate the data accuracy. Also the data validated and audited by Corporate HSE and Sustainability Auditor Team to ensure the reporting process was transparency and integrity. Table 2 summarizes the input and output variables identified by the case company, and Figure 1 presents the framework of the DEA model for sustainability measurement. In this model, the inputs are the total energy consumption (TEC), total fresh water intake (TFWI), and number of hours worked-employees (NOHWE). Good output is indicated by product volumes with solid lines, and bad outputs include the VOCs, total carbon dioxide $\left(\mathrm{TCO}_{2}\right)$, total waste (TW), and total recordable injury and illness rate (TRR).

Table 2. Input and output variables in the DEA model.

\begin{tabular}{ccccc}
\hline Abbreviation & Variable & Inputs or Outputs & Unit & Theoretical Background \\
\hline TEC & Total energy consumption & Input & TJ & {$[56-58]$} \\
\hline TFWI & Total fresh water intake & Input & $1000 \mathrm{M}^{3}$ & {$[59,60]$} \\
\hline NOHWE & $\begin{array}{c}\text { Number of hours } \\
\text { worked-employees }\end{array}$ & Input & hours & {$[61-63]$} \\
\hline $\mathrm{PV}$ & Production volume & Good output & tons & {$[64]$} \\
\hline $\mathrm{VOC}$ & Volatile organic compound & Bad output & tons & {$[58,65]$} \\
\hline $\mathrm{TCO}_{2}$ & Total carbon dioxide & Bad output & tons & {$[57,61,66]$} \\
\hline $\mathrm{TW}$ & Total waste & Bad output & tons & {$[62,67]$} \\
\hline $\mathrm{TRR}$ & $\begin{array}{c}\text { Total recordable (injury } \\
\text { and illness) rate }\end{array}$ & Bad output & per million hours & \\
\hline
\end{tabular}

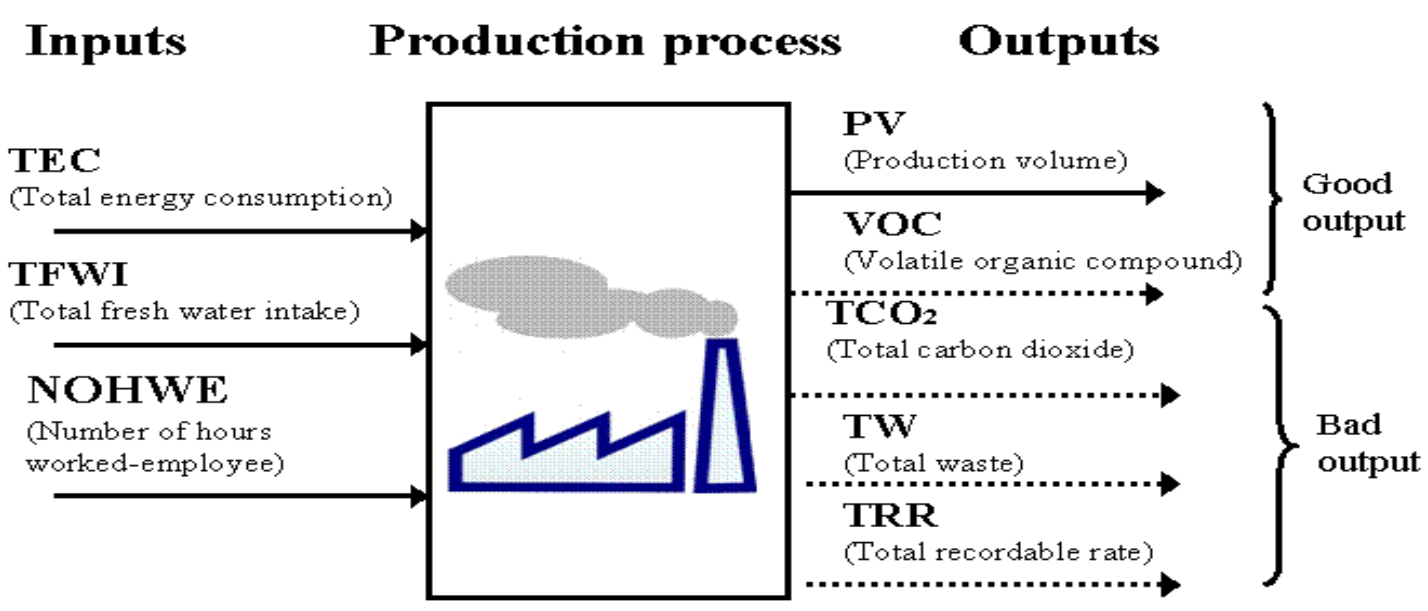

Figure 1. Concept of the DEA model for sustainability analysis.

The Dow Jones Sustainability Index gives significant attention to the total recordable rate (TRR) in the chemical industry, so it was included in the bad-output variables. The rule of thumb is that the number of DMUs must be twice that of the product of the inputs and outputs [68]. However, in this study, it was less than twice the product of inputs and outputs $(16<2(3 \times 5)$, so the discrimination 
was not favorable. We applied DEA window analysis to overcome the DMU shortage in the panel data [69]. We ran the bad-output model with the DEA solver for constant returns to scale (CRS) and variant returns to scale (VRS), using the software Statistica 7.0 to obtain the DMU average value for calculating the DEA window analysis.

\subsection{Numerical Results and Benchmarking}

Table 3 gives the average efficiency values of the 16 locations. The mean value using VRS (0.8260) was $29.76 \%$ higher than when using CRS (0.6365). In the previously mentioned review of over 100 papers, almost 50\% applied CRS to DEA for environment- and energy-related research. If we had used VRS in the DEA, the value would have required significant estimation [68], so we applied CRS in the DEA bad-output model to obtain the efficiency values of the 16 locations.

Table 3. Bad-output model (efficiency and standard deviation) with CRS and VRS

\begin{tabular}{cccccc}
\hline & Valid N & Mean & Minimum & Maximum & Std. Dev. \\
\hline Bad-output CRS efficiency & 16 & 0.6365 & 0.2330 & 0.9770 & 0.2430 \\
SD of bad-output CRS & 16 & 0.1089 & 0.0000 & 0.2677 & 0.0766 \\
Bad-output VRS efficiency & 16 & 0.8260 & 0.3964 & 0.9871 & 0.1925 \\
SD of bad-output VRS & 16 & 0.1134 & 0.0403 & 0.2167 & 0.0510 \\
\hline
\end{tabular}

Table 4 summarizes the efficiency scores and the slacks of bad output provided by the CRS model for the 16 Asian production sites of the case company. Figure 2 compares their bad-output CRS scores. Figures 3-9 are input and output slacks. The sustainability of the production sites was benchmarked using these scores as follows.

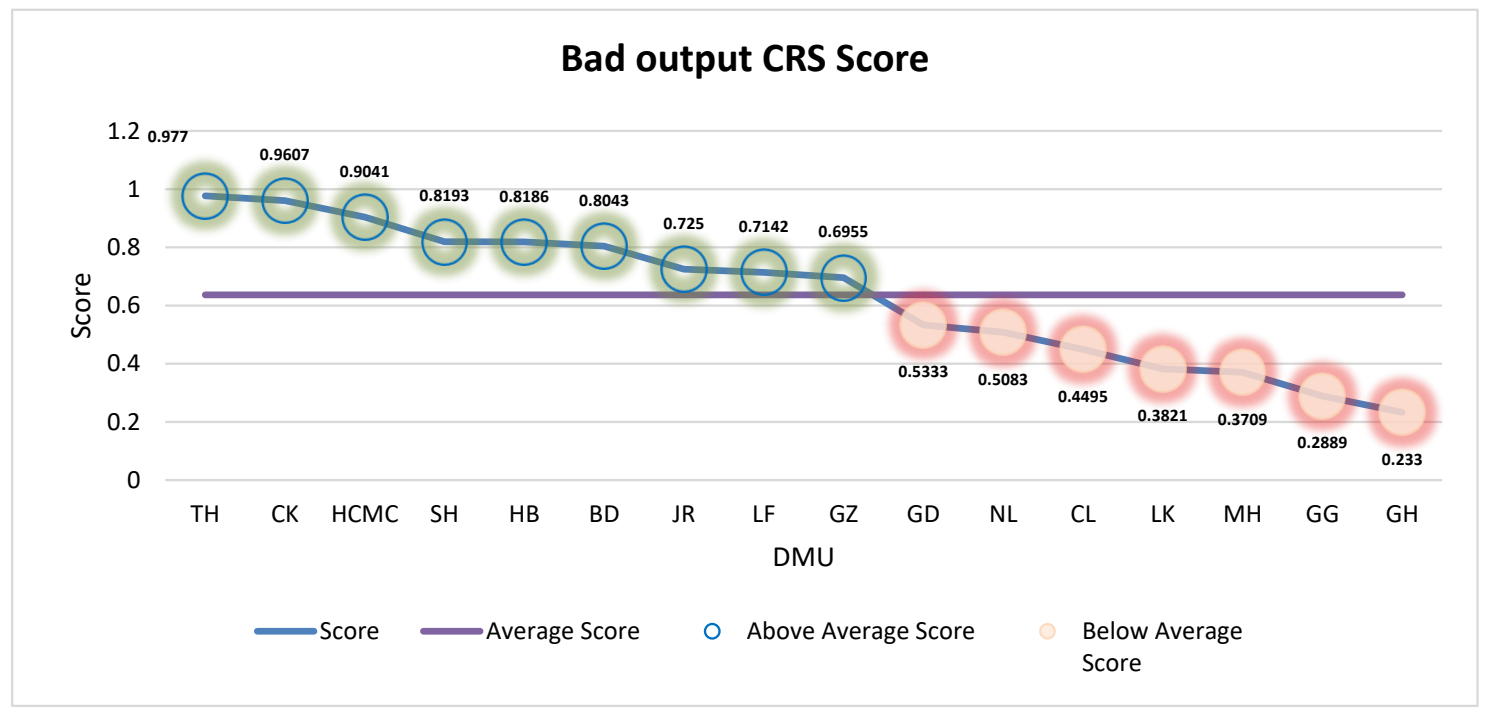

Figure 2. Bad-output CRS score for 16 locations in Asia. 
Table 4. Efficiency score and slacks of the bad-output CRS model

\begin{tabular}{|c|c|c|c|c|c|c|c|c|c|c|c|}
\hline Ranking & DMU & SBU & Score & TEC & TFWI & NOHWE & VOC & TW & $\mathrm{TCO}_{2}$ & TRR & PV \\
\hline & & & & Excess & Excess & Excess & Excess & Excess & Excess & Excess & Shortage \\
\hline 1 & $\mathrm{TH}$ & $\mathrm{S}$ & 0.9770 & 0.0124 & 0.1610 & 0 & 0.3157 & 0.4893 & 13.9187 & 0 & 0 \\
\hline 2 & CK & SE & 0.9607 & 0.0757 & 0.4501 & 1265.1719 & 0.0870 & 9.4776 & 6.1852 & 0 & 0 \\
\hline 3 & HCMC & SE & 0.9041 & 0.0695 & 0.6389 & 2815.5173 & 0.2334 & 3.9020 & 0 & 0 & 0 \\
\hline 4 & $\mathrm{SH}$ & $\mathrm{N}$ & 0.8193 & 0.7069 & 0.3643 & $135,989.3705$ & 2.6930 & 20.9123 & 67.8050 & 0.3505 & 0 \\
\hline 5 & HB & $\mathrm{S}$ & 0.8186 & 0.8294 & 0.6207 & 5188.9540 & 15.5750 & 1.6991 & 82.9202 & 2.0808 & 0 \\
\hline 6 & $\mathrm{BD}$ & SE & 0.8043 & 0.2145 & 0.2284 & $12,945.6591$ & 0.7893 & 15.1620 & 1.1877 & 0 & 0 \\
\hline 7 & $\mathrm{JR}$ & SE & 0.7250 & 0.2461 & 0.2164 & 8903.1724 & 0.0381 & 28.1252 & 9.1248 & 0 & 0 \\
\hline 8 & LF & $\mathrm{N}$ & 0.7142 & 0.2516 & 0.7133 & 7837.4302 & 1.8202 & 13.5822 & 23.4566 & 8.3610 & 0 \\
\hline 9 & GZ & $\mathrm{N}$ & 0.6955 & 2.4778 & 2.4274 & $16,439.6667$ & 5.6556 & 108.9671 & 200.0541 & 0 & 0 \\
\hline 10 & GD & $\mathrm{S}$ & 0.5333 & 1.6116 & 0 & 0 & 0 & 67.3471 & 152.3423 & 0 & 0 \\
\hline 11 & NL & SE & 0.5083 & 4.1261 & 1.3553 & $56,191.0241$ & 4.3872 & 111.2965 & 167.8347 & 2.1176 & 0 \\
\hline 12 & CL & $\mathrm{N}$ & 0.4495 & 3.7675 & 4.0360 & $13,244.9842$ & 1.8915 & 26.5842 & 224.9505 & 0 & 0 \\
\hline 13 & LK & SE & 0.3821 & 3.0721 & 3.0612 & $82,835.0971$ & 14.6244 & 69.6027 & 115.5707 & 2.9266 & 0 \\
\hline 14 & $\mathrm{MH}$ & $\mathrm{S}$ & 0.3709 & 4.7389 & 0.3378 & $32,903.0345$ & 3.8806 & 7.1392 & 480.7608 & 0 & 0 \\
\hline 15 & GG & $S$ & 0.2889 & 1.1947 & 0 & $369,571.6667$ & 0 & 0 & 121.7589 & 0.6095 & 0 \\
\hline 16 & GH & $\mathrm{SE}$ & 0.2330 & 0.2122 & 0.3346 & $43,370.6998$ & 0.9788 & 5.8021 & 5.4958 & 8.3541 & 0 \\
\hline
\end{tabular}

Abbreviation of SBU—Southeast Asia: SE; South Asia: S; North Asia: N. 


\section{TEC Slacks}

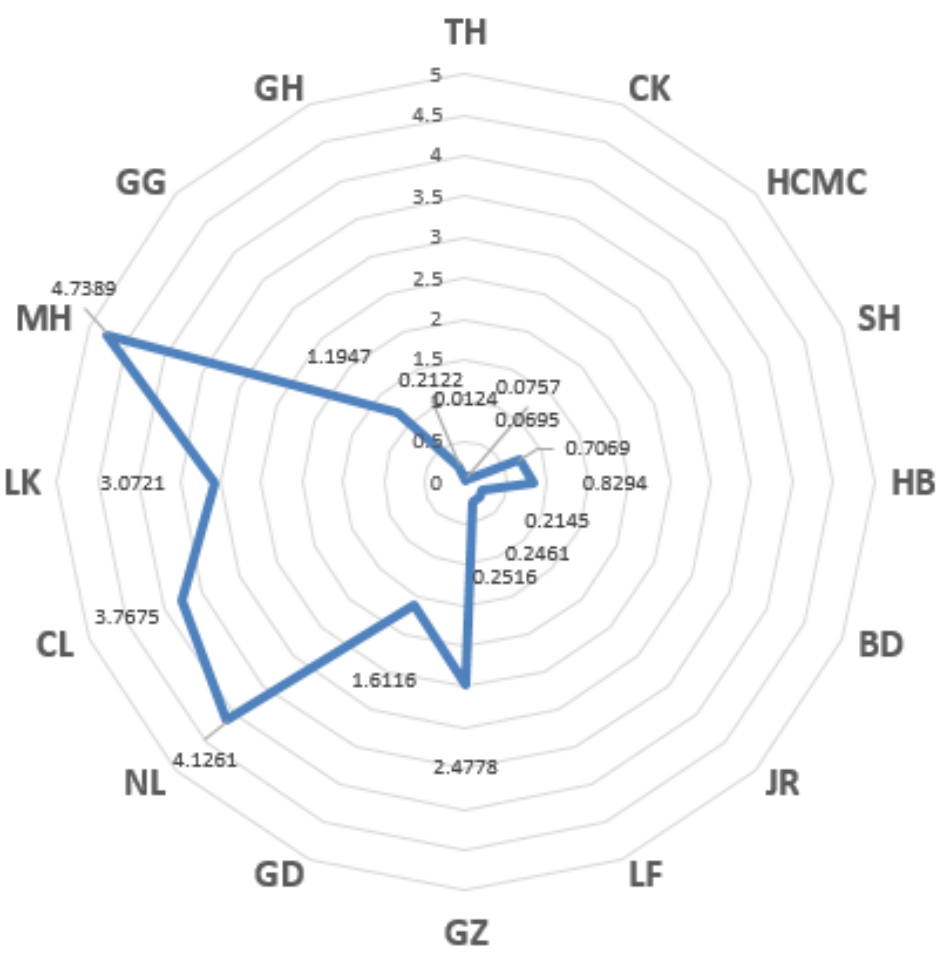

Figure 3. TEC Slacks.

\section{TFWI Slacks}

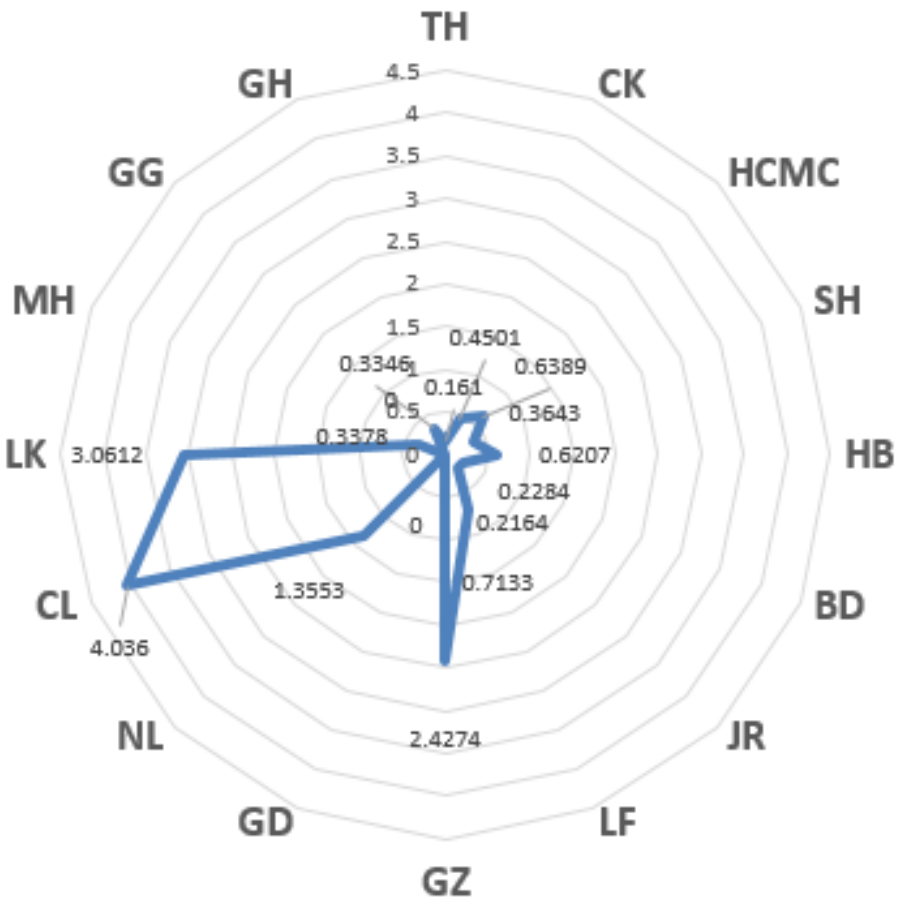

Figure 4. TFWI Slacks. 


\section{NOHWE Slacks}

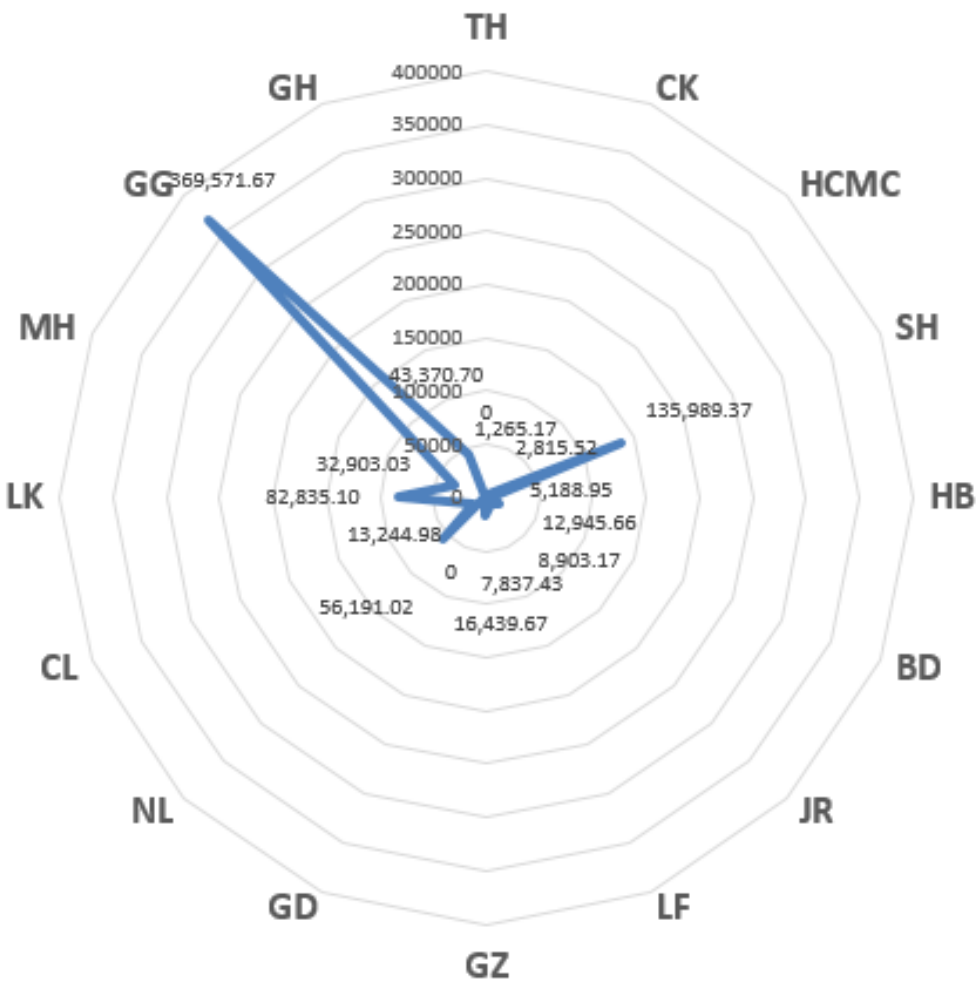

Figure 5. NOHWE Slacks.

\section{$\mathrm{TCO}_{2}$ Slacks}

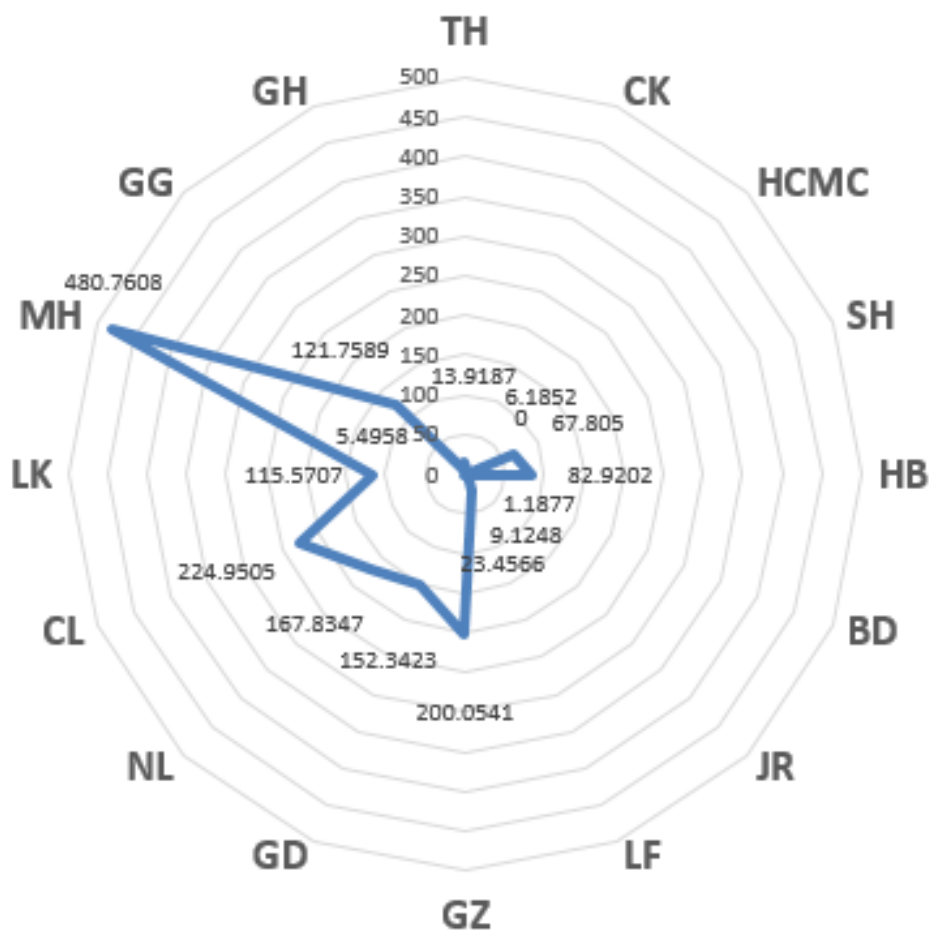

Figure 6. $\mathrm{TCO}_{2}$ Slacks. 


\section{VOC Slacks}

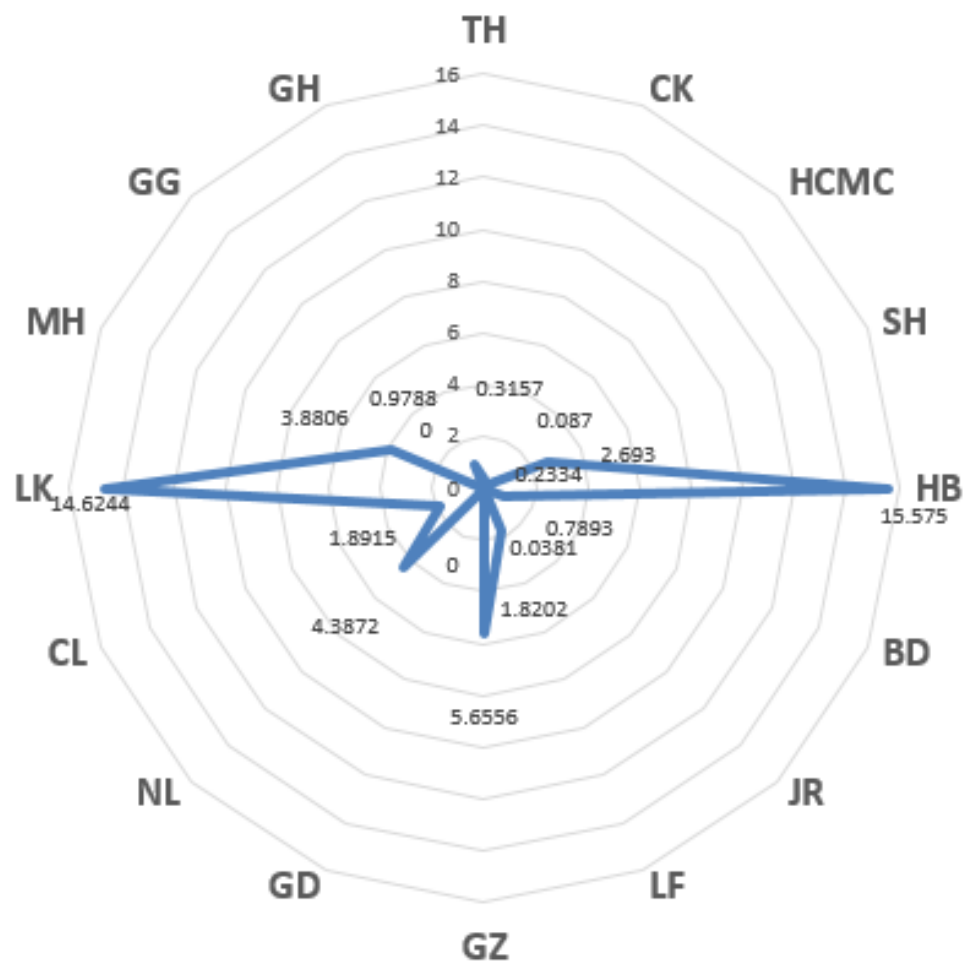

Figure 7. VOC Slacks.

\section{TW Slacks}

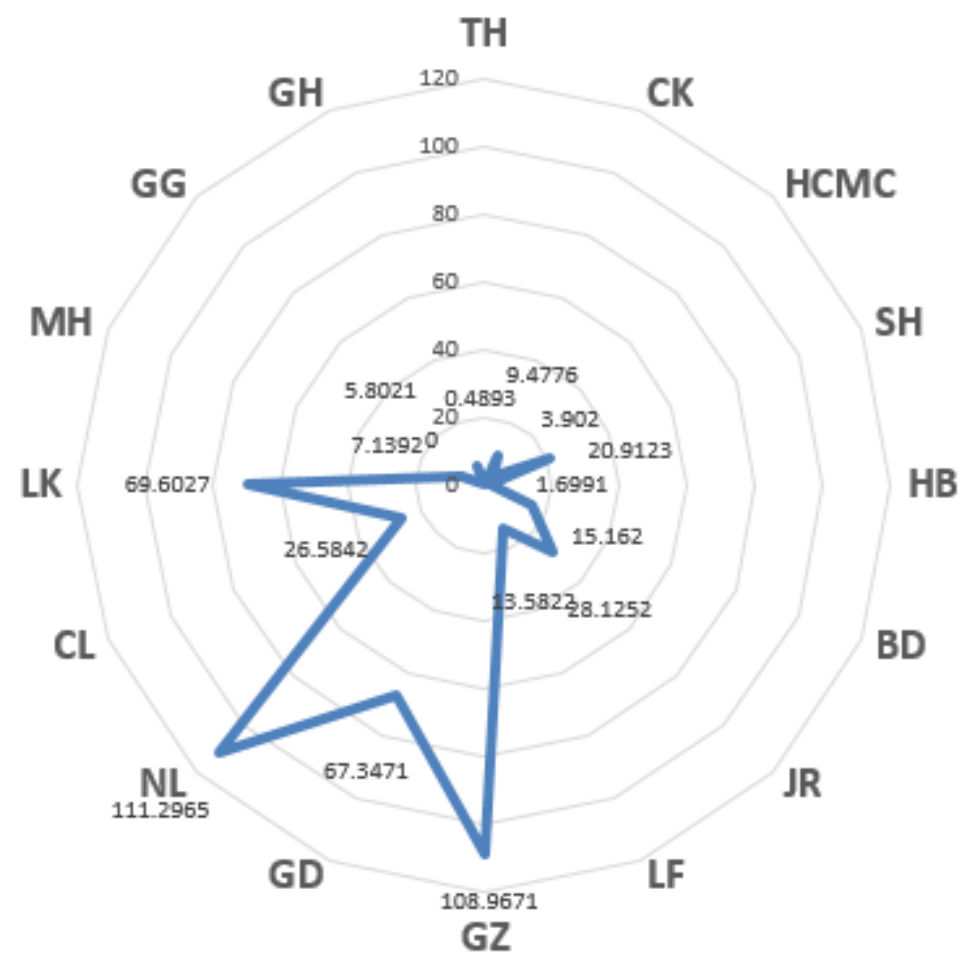

Figure 8. TW Slacks. 


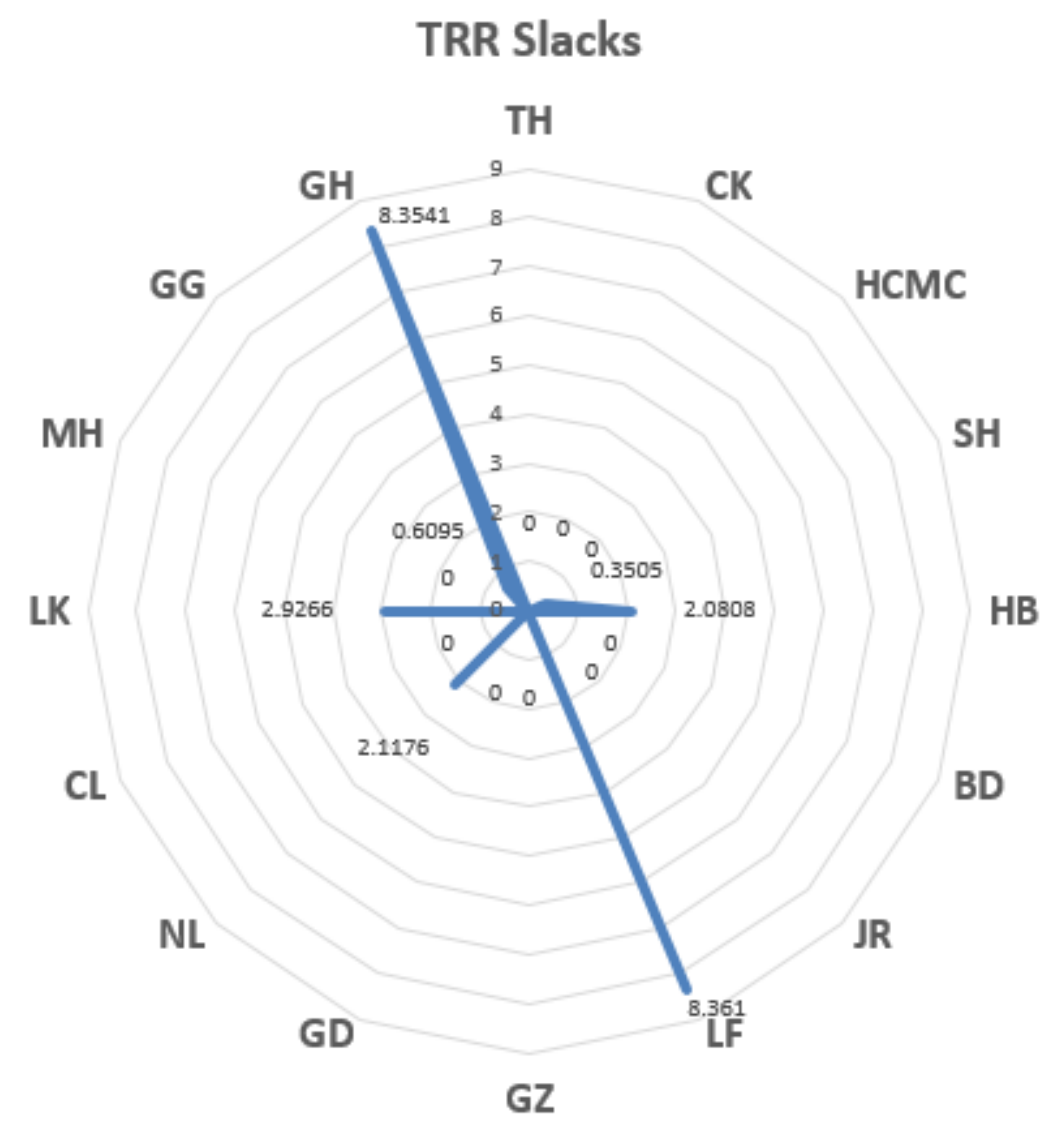

Figure 9. TRR Slacks.

First place: The factory TH located in India achieved the highest efficiency score (0.977). For NOHWE and TRR, it scored zero slacks. The slacks for TEC, TFWI, and TW were the lowest of the 16 locations and could thus be used as a benchmark. However, TH could still improve its performance in $\mathrm{TCO}_{2}$ and VOC by benchmarking; $\mathrm{HCMC}$ in Vietnam showed the best performance on these variables, with zero slacks for both.

Second place: The CK factory in Indonesia achieved the second highest efficiency score (0.9607), with zero slacks for TRR. This location also achieved slacks scores for TEC, NOHWE, and VOC that were in the best 3 of all 16 locations, and could thus serve as a reference for good practice.

Third place: The HCMC factory in Vietnam achieved the third highest efficiency score (0.9041), with zero slacks for $\mathrm{TCO}_{2}$ and TRR. This location also achieved slacks scores for TEC, NOHWE, and TW that were in the best 3 of all 16 locations, and could thus serve as a reference for good practice.

Fourth place: The SH factory in China achieved the fourth highest efficiency score (0.8193). The slacks of all inputs and outputs were above the average for the 16 locations.

Fifth place: The HB factory in India achieved the fifth highest efficiency score (0.8186). This location achieved a slacks score for TW that was in the best 3 of all 16 locations, and could thus be a reference for good practice.

Sixth place: The BD factory in Vietnam achieved the sixth highest efficiency score (0.8043), with zero slacks for TRR. This location also achieved slacks scores for $\mathrm{TCO}_{2}$ and TFWI that were in the best 3 of all 16 locations, and could thus be a reference for good practice.

Seventh place: The JR factory in Singapore achieved the seventh highest efficiency score (0.725), with zero slacks for TRR. This location also achieved slacks scores for TFWI and VOC that were in the best 3 of all 16 locations, and could thus be a reference for good practice.

Eighth place: The LF factory in China achieved the eighth highest efficiency score (0.7142). The slacks for most inputs and outputs were at the average level of the 16 locations. This location had 
the worst slacks score for TRR, which could be improved. This location could derive benchmarks from other locations that performed well in this area (i.e., TH, CK, HCMC, BD, JR, GZ, CL, and MH).

Ninth-sixteenth places: The production factories GZ, NL, CL, LK, MH, and GH could learn from the best-performing locations of TH, CK, HCMC, SH, GD, and GG. Although the worst-performing factories were warehouse logistics centers without production activities, they could still improve practices in areas such as energy and water conservation, and could optimize their logistics routes to reduce $\mathrm{TCO}_{2}$ output.

It was inevitable to produce undesirable output from input resources on the manufacturing process. All the slacks of 16 manufacturing sites were not possible to achieve 'zero' emission on environmental impact even the first place TH that demonstrated slacks o VOC and TCO2 emission and total waste generation from resource inputs on total energy consumption and total fresh water intake. The manufacturing productivity is the best at TH site, they demonstrate their passion to find possible innovative solutions to improve environmental performance to reduce water and energy consumption and reduce environmental impact. So other sites benchmark from TH for sharing and learning.

The case company holds regular meeting to share best practices for nature resources conservation and lower impact to environment. They conducted baseline survey for energy and water consumption and involved engineering team to support innovative techniques to every site on renewable energy, water and waste recycle program, bulk manufacturing instead of small batch of production, increase boiler efficiency, HSE team monitors the solutions effectiveness and better control for achieving the environmental target. Also they promote the sustainability campaign to promote green products to engage with customers and employees for environmental friendly. Employees take initiatives for resource conservation projects improvement for competition and reward for promoting the environmental culture. These are value-added initiatives for sustainable improvements to mitigate impact to the environment and protect stakeholder's health and safety.

Again, by geographical location, we clustered the selected 16 production sites of the case company into three subgroups: subgroup 1 included the factories located in North Asia (China and Taiwan), subgroup 2 included the sites located in South Asia (India), and subgroup 3 those in Southeast Asia (Singapore, Thailand, Vietnam, Indonesia, Malaysia, and Papua New Guinea). We then conducted an ANOVA test to analyze the performance difference of the three groups in terms of their bad-output CRS efficiency. The test results are presented in Table 5 , which shows that the three subgroups did not differ significantly in their bad outputs $(p=0.912129>0.05)$. We therefore deduced that the sustainability performance of factories located in North, South, and Southeast Asia were statistically similar. The reason is that the case company implemented HSE \& Sustainability management system for more than decades that strictly governed by Corporate HSE \& Sustainability so the performance was insignificant. The sustainability culture in the global company was embedded mature for continuous improvement and business continuity in the long run.

Table 5. ANOVA of bad-output difference

\begin{tabular}{ccccccccc}
\hline \multirow{2}{*}{ Variable } & \multicolumn{7}{c}{$\begin{array}{c}\text { Analysis of Variance (Bad-Output Efficiency. sta.) } \\
\text { Marked Effects are Significant at } \boldsymbol{p}<\mathbf{0 . 0 5 0 0 0 0}\end{array}$} \\
\cline { 2 - 9 } & SS Effect & df Effect & MS Effect & SS Error & df Error & MS Error & F & $p$ \\
\hline $\begin{array}{c}\text { Bad-output CRS } \\
\text { efficiency }\end{array}$ & 0.0124 & 2 & 0.0062 & 0.8732 & 13 & 0.0672 & 0.0926 & 0.9121 \\
\hline $\begin{array}{c}\text { SD of } \\
\text { bad-output CRS }\end{array}$ & 0.0269 & 2 & 0.0134 & 0.0612 & 13 & 0.0047 & 2.8546 & 0.0938 \\
\hline
\end{tabular}

\subsection{Sensitivity Analysis}

We conducted a sensitivity analysis on Table 6 by running DEA bad-output model and window analysis in order to see how score would change by removing every input variable (total energy consumption, Total Fresh Water Intake-TFWI, Number of Hours Work Employees-NOHWE, and bad 
output variables ( $\mathrm{VOC}, \mathrm{CO}_{2}$, total waste, and total recordable rate). It demonstrated the changes rate is slightly between $0-9 \%$ that did not affect much to the efficiency. The performance will be reduced for $15 \%$ if we exclude variable of TFWI. The water consumption is critical for the case company because it required a fix percent of fresh water in the manufacturing process.

Table 6. Sensitivity analysis

\begin{tabular}{ccccccccc}
\hline DMU & $\begin{array}{c}\text { Original } \\
\text { Score }\end{array}$ & $\begin{array}{c}\text { Remove } \\
\text { TEC }\end{array}$ & $\begin{array}{c}\text { Remove } \\
\text { TFWI }\end{array}$ & $\begin{array}{c}\text { Remove } \\
\text { NOHWE }\end{array}$ & $\begin{array}{c}\text { Remove } \\
\text { VOC }\end{array}$ & $\begin{array}{c}\text { Remove } \\
\text { CO }_{2}\end{array}$ & $\begin{array}{c}\text { Remove } \\
\text { TW }\end{array}$ & $\begin{array}{c}\text { Remove } \\
\text { TRR }\end{array}$ \\
\hline TH & 0.977 & 0.9678 & 0.9767 & 0.9144 & 0.9674 & 0.9762 & 0.8781 & 0.9566 \\
\hline CK & 0.9607 & 0.9559 & 0.9492 & 0.9568 & 0.937 & 0.9584 & 0.942 & 0.9241 \\
\hline HCMC & 0.9041 & 0.8878 & 0.9136 & 0.8857 & 0.9053 & 0.7924 & 0.8312 & 0.8839 \\
\hline SH & 0.8193 & 0.7944 & 0.506 & 0.8858 & 0.8328 & 0.8138 & 0.7142 & 0.8207 \\
\hline HB & 0.8186 & 0.8303 & 0.7458 & 0.8004 & 0.8261 & 0.82 & 0.4404 & 0.8076 \\
\hline BD & 0.8043 & 0.7896 & 0.7734 & 0.8391 & 0.8201 & 0.3058 & 0.7964 & 0.7933 \\
\hline JR & 0.725 & 0.7169 & 0.6205 & 0.7548 & 0.6313 & 0.6873 & 0.7063 & 0.6675 \\
\hline LF & 0.7142 & 0.6332 & 0.6168 & 0.7 & 0.7322 & 0.705 & 0.5964 & 0.7102 \\
\hline GZ & 0.6955 & 0.7259 & 0.648 & 0.6171 & 0.7639 & 0.6884 & 0.6653 & 0.6672 \\
\hline GD & 0.5333 & 0 & 0.4 & 0.4 & 0.5 & 0.5714 & 0.5714 & 0.5208 \\
\hline NL & 0.5083 & 0.5504 & 0.4045 & 0.5142 & 0.5414 & 0.4995 & 0.5101 & 0.4669 \\
\hline CL & 0.4495 & 0.5005 & 0.4354 & 0.3576 & 0.4382 & 0.4574 & 0.4007 & 0.4247 \\
\hline LK & 0.3821 & 0.3757 & 0.3033 & 0.4107 & 0.4091 & 0.3732 & 0.3857 & 0.372 \\
\hline MH & 0.3709 & 0.4704 & 0.2 & 0.3769 & 0.3932 & 0.3886 & 0.34 & 0.3716 \\
\hline GG & 0.2889 & 0.4333 & 0 & 0.4333 & 0.2768 & 0.3214 & 0.2783 & 0.2942 \\
\hline GH & 0.233 & 0.1829 & 0.1848 & 0.3235 & 0.2492 & 0.2267 & 0.2217 & 0.2604 \\
\hline Average & 0.6365 & 0.6134 & 0.5424 & 0.6356 & 0.639 & 0.5991 & 0.5799 & 0.6214 \\
\hline Performance & & $-4 \%$ & $-15 \%$ & $0 \%$ & $0 \%$ & $-6 \%$ & $-9 \%$ & $-2 \%$ \\
\hline Change $\%$ & & & & & & & &
\end{tabular}

\section{Discussions}

The DEA method has been applied to many industrial scenarios to test the efficiency of resource deployment and economic outcomes, but both the input resources and the output products are typically assumed to be normal goods. We considered undesired outputs such as $\mathrm{CO}_{2}$ emissions, wasted water, volatile organic compounds, and employees' injuries and illnesses as bad outputs in measuring the production efficiency of the chemical manufacturing company in the DEA model. The implications are presented as follows:

\subsection{Theoretical Implications}

Yan et al. (2017) applied a non-radial DEA model to assess the sustainability performance of the construction industry in 30 provinces in China, the inputs of are (number of employee, energy consumption, total assets, and construction benefits). The desirable outputs are (newly increased value and transferred value) and undesirable out is ( $\mathrm{CO}_{2}$ emission during construction process). Besides that, they conducted a regional input-output model to adjust the needs for improvement in provinces toward optimizing their performance [70]. Zhou and $\mathrm{Hu}$ (2017) proposed a revision of a two-stage DEA model to measure the sustainability performance of triple-bottom line (environment, economic, society) in the railway industry in China, which the inputs are (labor, land, and capital), the intermediate outputs are (railway mileage and railway density), the desire outputs are (passenger turnover, freight turnover, and average salary growth), and the undesirable output is (dust) from the production stage to service stage [71]. Oggioni et al. (2011) proposed a distance directional function 
of the DEA model to assess the inputs (labor, materials, capacity, and energy), desirable outputs (cement), and undesirable outputs (carbon dioxide) in the chemical cement industry across 21 countries. They used the DEA tool to improve the cement business by reducing undesirable emissions in line with environmental policies and improve sustainable performance [72]. $\mathrm{Li}$ and $\mathrm{Hu}$ (2012) applied an undesirable slacks-based measure of the DEA model to access the inputs (energy consumption, capital stock, and labor), desirable outputs (real gross domestic product (GDP), and undesirable outputs (carbon and sulfate dioxide) across 30 regions in China. They identified four factors and developed a regression model for increasing the energy efficiency ratio to GDP of R\&D expenditure on GDP, degree of foreign dependence, secondary industry to GDP, and government subsidies of industrial pollution prevention. The government subsequently considered changing the country's high dependence on coal to reduce both energy consumption and carbon and sulfate dioxide emissions [73]. Hua et al. (2007) proposed non-radial linear programing of the DEA model to assess the non-discretionary input (emission quotas of biochemical oxygen demand), inputs (labor and capital), and desirable (paper) and undesirable (biochemical oxygen demand) outputs of 32 paper mills situated along the Hui River in China. This approach can improve performance by reducing non-discretional inputs and undesirable outputs [74].

Above DEA models of non-radial, SBM, DDF, and two-stage for improving sustainability performance to minimize input and undesirable output. The central concept of the proposed method is to use DEA techniques to reduce both inputs and undesirable outputs, which can be regarded as inferior goods, to produce ecological and economic effects. The case applied for DEA bad-output model that is substantially distinct from that of the traditional DEA model, which attempts to achieve maximum favorable outputs by minimizing inputs alone.

\subsection{Practical Implications}

The manufacturing industry almost inevitably generates negative outputs in production processes. For a global manufacturing company with multiple production sites worldwide, benchmarking the sustainability performance of production factories in different locations with specific conditions and advantages is a challenge for decision makers.

In the application case, a global chemical manufacturing company applied the framework of the DEA method and the bad-output model to benchmark its 16 production factories in Asia. Setup, energy, water, and manpower were identified as the input resources in the model, and $\mathrm{CO}_{2}$ emissions, wasted water, chemical compounds, and laborers' injuries were considered bad outputs. Relating these measures to corporate social responsibility (CSR) allows the quality management systems ISO14001 and ISO26000 to be included. If we consider energy and fresh water as the inputs and production volume as the output, the case company can achieve 'green' production, with chemical compounds, wasted materials, and $\mathrm{CO}_{2}$ emissions as bad outputs. The requirements of WEEE, $\mathrm{REACH}$, and the United Nations Framework Convention on Climate Change (UNFCCC) can then be met.

By regarding sector man-hours as the input and employees' injuries and illness as bad outputs, the industrial safety dimension is considered and the stakeholders' priority of CSR is supported. Many interrelated business benefits can be derived from increased employee engagement, such as increased loyalty, improved recruitment, increased retention, and higher productivity. By incorporating safety indices into sustainability metrics, employees feel that their company is concerned about them on the personal and professional levels. Over the long term, a company's human capital can conduct business in a sustainable way, thus encouraging business growth and environmental awareness.

\subsection{Limitations and Future Research}

Data collection is a potential technical problem in the application of DEA for sustainability, as the number of DMUs influences decision quality when the DEA method is used. In the case study, operational data from only 16 production sites were collected from 2018 to 2020, so DEA window analysis was used to tackle the problem of a small number of DMUs, according to the rule of thumb 
less than twice the product of inputs and outputs to overcome this shortage and to increase the discrimination of the panel data. It can be extended to apply DEA Malmquist measure productivity changes over time (Asmild et al., 2004).

The evaluation process could be taken as a practical reference for the chemical industry to benchmark the sustainable performance of production sites and provide numerous comparative advantages. Future research can apply it to other regions or industries for benchmarking sustainability performance.

The research was mainly on environmental and societal dimensions. The financial data is protected at the case company that is not included for benchmarking, so it can be considered for future research.

The societal index was the total recordable rate that is lagging in the study, so it can be considered more of a leading safety index as the good outputs to prevent injuries rather than injury happened for taking investigation and improvement actions, such as contact rate and no. of base safety behaviors, no. of leaders, and employee safety engagement for contributing to the value-added process in global manufacturing.

\subsection{Contributions}

The contributions of Sustainable Manufacturing improvement summarized as the following Figure 10. The criteria for benchmarking shall have the definition, target, scope, and object that can collect the baseline for measurement. The case applied DEA bad-output model that can minimize resource input and undesirable output by maximizing the good output. Therefore, the DMU ranked at the top for each input or bad-output is the benchmark for other DMUs in the organization or network, which can engage and satisfy employees or customers for sustainable continuous improvement on ecofriendliness or mitigate the environmental impact while pursuing manufacturing excellence.

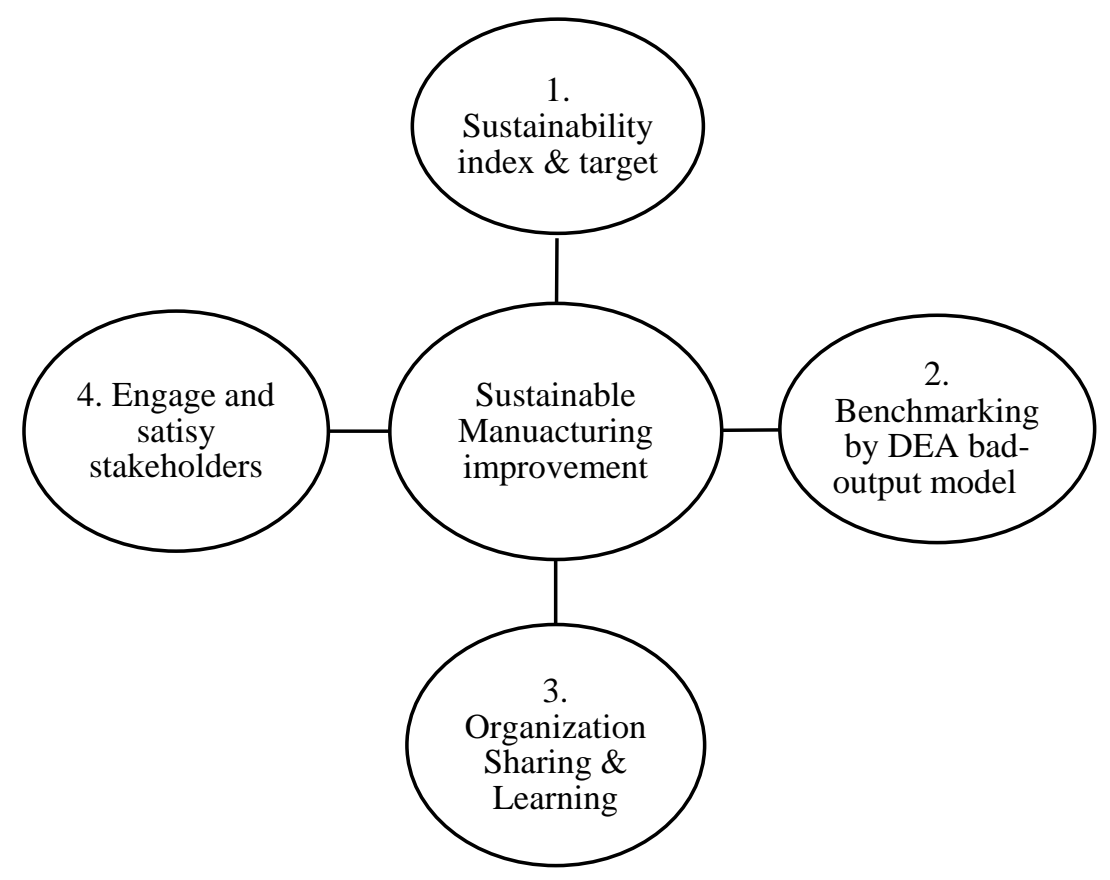

Figure 10. Contributions for the sustainable manufacturing.

\section{Conclusions}

Manufacturing companies are particularly concerned with how CSR can enable stakeholders to meet the expectations of customers, the community, suppliers, local authorities, and employees. By maximizing the production volume across all branches, the global chemical manufacturer in the application case faced negative outputs from its processes, causing environmental deterioration and affecting human health. Their challenge was to manage sustainable performance at multiple manufacturing sites. We proposed a DEA bad-output model to evaluate the efficiency of DMUs and 
promote continued improvements through learning good practice from the DMUs at the frontier. The model was applied to minimize the resource inputs (man hours, fresh water, and energy consumption) and the bad outputs (total recordable injury and illness rate, solid waste, water, carbon dioxide, and volatile organic compounds) by maximizing the finished goods, all of which were considered aspects of the triple bottom line (ecological, economic, and social). Other research has almost exclusively focused on the ecological and economic effects. Safety-related indices, such as the input resources of manpower hours and the bad output of reportable injury and illness, were also considered in terms of CSR. The results suggest that employees are willing to sustainably enhance their productivity and performance by minimizing the effect on the ecology and their health. This study can serve as a reference for the global manufacturing industry to measure, manage, and monitor sustainable performance at multiple sites and create value-added processes that satisfy stakeholders.

Author Contributions: Conceptualization, J.-D.L., M.-N.F.; methodology, J.-D.L., W.-H.T., M.-N.F.; software, S.C.; validation, J.-D.L., M.-N.F.; formal analysis, J.-D.L., M.-N.F., S.C., W.-H.T.; investigation, M.-N.F.; resources, M.-N.F.; data curation, J.-D.L.; writing—original draft preparation, M.-N.F.; writing—review and editing, J.-D.L., W.-H.T.; visualization, M.-N.F.; supervision, J.-D.L.; project administration, J.-D.L.; funding acquisition, J.-D.L., W.-H.T. All authors have read and agreed to the published version of the manuscript.

Funding: This research was supported by the Ministry of Science and Technology of Taiwan, under the grant MOST109-2410-H-008-029-MY2 \& MOST108-2410-H-008-060.

Acknowledgments: In addition, the authors would like to thank Julia Gauntley, a former Corporate Regional HSE\&S Manager of a multinational chemical company, for her professional guidance.

Conflicts of Interest: The authors declare no conflict of interest.

\section{References}

1. Dao, V.; Langella, I.; Carbo, J. From green to sustainability: Information Technology and an integrated sustainability framework. J. Strat. Inf. Syst. 2011, 20, 63-79. [CrossRef]

2. Valase, K.; Raut, D.N. Mediation analysis of multiple constructs in the relationship between manufacturing and technology and environmental constructs in structural equation model for sustainable manufacturing. Int. J. Adv. Manuf. Technol. 2018, 101, 1887-1901. [CrossRef]

3. Zhu, Q.; Sarkis, J.; Lai, K.-H. Confirmation of a measurement model for green supply chain management practices implementation. Int. J. Prod. Econ. 2008, 111, 261-273. [CrossRef]

4. European Commission. The Restriction of Hazardous Substances (RoHS) Regulations on Electric and Electronics Equipment, 2002. Available online: http://www.rohsguide.com (accessed on 20 January 2017).

5. European Commission. The Registration, Evaluation, Authorization and Restriction of Chemicals, 2006. Available online: http://ec.europa.eu/index_en.htm (accessed on 20 January 2017).

6. Code of Federal Regulations. Title 40 for regulations of US Environmental Protection Agency (EPA), 2011. Available online: http://www.gpo.gov (accessed on 20 January 2017).

7. Hart, S.L. Beyond greening: Strategies for a sustainable world. Harv. Bus. Rev. 1997, 75, 66-76.

8. Khan, M.; Lockhart, J.; Bathurst, R. A multi-level institutional perspective of corporate social responsibility reporting: A mixed-method study. J. Clean. Prod. 2020, 265, 121739. [CrossRef]

9. Chen, T.-C.T. Competitive and Sustainable Manufacturing in the Age of Globalization. Sustainability 2016, 9, 26. [CrossRef]

10. Kishawy, H.; Hegab, H.; Mahdi, E. Design for Sustainable Manufacturing: Approach, Implementation, and Assessment. Sustainability 2018, 10, 3604. [CrossRef]

11. Abdul-Rashid, S.H.; Sakundarini, N.; Ghazilla, R.A.R.; Thurasamy, R. The impact of sustainable manufacturing practices on sustainability performance. Int. J. Oper. Prod. Manag. 2017, 37, $182-204$. [CrossRef]

12. Zhou, P.; Ang, B.; Poh, K. A survey of data envelopment analysis in energy and environmental studies. Eur. J. Oper. Res. 2008, 189, 1-18. [CrossRef]

13. World Commission on Environment and Development. Our Common Future; Oxford University Press: Oxford, UK, 1987; p. 347. 
14. Elkington, J. Cannibals with Forks: The Triple-Bottom-Line of 21st Century; New Society Publishers: Gabriola Island, BC, Canada, 1998.

15. Wu, Y.; Swain, R.E.; Jiang, N.; Qiao, M.; Wang, H.; Bai, J.; Zhou, X.; Sun, X.; Xu, J.; Xu, M.; et al. Design with nature and eco-city design. Ecosyst. Health Sustain. 2020, 6, 1-10. [CrossRef]

16. Zeleny, M. Strategy as action: From Porter to anti-Porter. Internat. J. Strat. Decis. Sci. 2010, 1, 1-22. [CrossRef]

17. Kleindorfer, P.; Singhal, K.; van Wassenhove, L.N. Sustainable Operations Management. Prod. Oper. Manag. 2009, 14, 482-492. [CrossRef]

18. Helmers, E.; Dietz, J.; Weiss, M. Sensitivity Analysis in the Life-Cycle Assessment of Electric vs. Combustion Engine Cars under Approximate Real-World Conditions. Sustainability 2020, 12, 1241. [CrossRef]

19. Daddi, T.; Nucci, B.; Iraldo, F. Using Life Cycle Assessment (LCA) to measure the environmental benefits of industrial symbiosis in an industrial cluster of SMEs. J. Clean. Prod. 2017, 147, 157-164. [CrossRef]

20. Wang, B.; Gebreslassie, B.H.; You, F. Sustainable design and synthesis of hydrocarbon biorefinery via gasification pathway: Integrated life cycle assessment and technoeconomic analysis with multiobjective superstructure optimization. Comput. Chem. Eng. 2013, 52, 55-76. [CrossRef]

21. Koroneos, C.J.; Nanaki, E. Integrated solid waste management and energy production-A life cycle assessment approach: The case study of the city of Thessaloniki. J. Clean. Prod. 2012, 27, 141-150. [CrossRef]

22. Green, K.W.; Inman, R.A.; Sower, V.E.; Zelbst, P.J. Impact of JIT, TQM and green supply chain practices on environmental sustainability. J. Manuf. Technol. Manag. 2019, 30, 26-47. [CrossRef]

23. Fercoq, A.; Lamouri, S.; Carbone, V. Lean/Green integration focused on waste reduction techniques. J. Clean. Prod. 2016, 137, 567-578. [CrossRef]

24. Li, Y.; Sawhne, R.S.; Wilck, J.H. Applying Bayesian Network Techniques to Prioritize Lean Six Sigma Efforts. Int. J. Strat. Decis. Sci. 2013, 4, 1-15. [CrossRef]

25. Acharya, T.K. Material handling and process improvement using lean manufacturing principles. Int. J. Ind. Eng. 2011, 18, 357-368.

26. Koh, S.; Morris, J.; Ebrahimi, S.M.; Obayi, R. Integrated resource efficiency: Measurement and management. Int. J. Oper. Prod. Manag. 2016, 36, 1576-1600. [CrossRef]

27. Gavronski, I.; Klassen, R.D.; Vachon, S.; Nascimento, L.F. A resource-based view of green supply management. Transp. Res. Part E Logist. Transp. Rev. 2011, 47, 872-885. [CrossRef]

28. Aragón-Correa, J.A.; Hurtado-Torres, N.; Sharma, S.; García-Morales, V.J. Environmental strategy and performance in small firms: A resource-based perspective. J. Environ. Manag. 2008, 86, 88-103. [CrossRef] [PubMed]

29. Sudarto, S.; Takahashi, K.; Morikawa, K. Efficient flexible long-term capacity planning for optimal sustainability dimensions performance of reverse logistics social responsibility: A system dynamics approach. Int. J. Prod. Econ. 2017, 184, 179-192. [CrossRef]

30. García-Rodríguez, F.J.; Castilla-Gutiérrez, C.; Bustos-Flores, C. Implementation of reverse logistics as a sustainable tool for raw material purchasing in developing countries: The case of Venezuela. Int. J. Prod. Econ. 2013, 141, 582-592. [CrossRef]

31. Jayant, A.; Gupta, P.; Garg, S.K. Reverse logistics: Perspectives, empirical studies and research directions. Int. J. Ind. Eng. 2012, 19, 369-388.

32. Sihvonen, S.; Partanen, J. Eco-design practices with a focus on quantitative environmental targets: An exploratory content analysis within ICT sector. J. Clean. Prod. 2017, 143, 769-783. [CrossRef]

33. Casamayor, J.L.; Su, D. Integration of eco-design tools into the development of eco-lighting products. J. Clean. Prod. 2013, 47, 32-42. [CrossRef]

34. Borchardt, M.; Sellitto, M.A.; Pereira, C.M.; Gomes, L.P. Ecodesign case studies for furniture companies using the analytic hierarchy process. Int. J. Ind. Eng. 2012, 19, 330-340.

35. Tasdemir, C.; Gazo, R.; Quesada, H.J. Sustainability benchmarking tool (SBT): Theoretical and conceptual model proposition of a composite framework. Environ. Dev. Sustain. 2019, 22, 6755-6797. [CrossRef]

36. da Costa, L.G.; Ferreira, J.C.E.; Kumar, V.; Garza-Reyes, J.A. Benchmarking of sustainability to assess practices and performances of the management of the end of life cycle of electronic products: A study of Brazilian manufacturing companies. Clean Technol. Environ. Policy 2020, 1-17. [CrossRef]

37. Radovanov, B.; Dudić, B.; Gregus, M.; Horvat, A.M.; Karovič, V. Using a Two-Stage DEA Model to Measure Tourism Potentials of EU Countries and Western Balkan Countries: An Approach to Sustainable Development. Sustainability 2020, 12, 4903. [CrossRef] 
38. Ang, B.; Zhang, F. A survey of index decomposition analysis in energy and environmental studies. Energy 2000, 25, 1149-1176. [CrossRef]

39. Zhou, P.; Ang, B.; Poh, K. Measuring environmental performance under different environmental DEA technologies. Energy Econ. 2008, 30, 1-14. [CrossRef]

40. Chodakowska, E.; Nazarko, J. Assessing the Performance of Sustainable Development Goals of EU Countries: Hard and Soft Data Integration. Energies 2020, 13, 3439. [CrossRef]

41. Abbaspour, M.; Lotfi, F.H.; Karbassi, A.; Roayaei, E.; Nikoomaram, H. Development of a model to assess environmental performance, concerning HSE-MS principles. Environ. Monit. Assess. 2009, 165, 517-528. [CrossRef] [PubMed]

42. Azadeh, A.; Farmand, A.H.; Sharahi, Z.J. Performance assessment and optimization of HSE management systems with human error and ambiguity by an integrated fuzzy multivariate approach in a large conventional power plant manufacturer. J. Loss Prev. Process. Ind. 2012, 25, 594-603. [CrossRef]

43. Charnes, A.; Cooper, W.W.; Rhodes, E. Measuring the efficiency of decision-making units. Eur. J. Oper. Res. 1978, 2, 429-444. [CrossRef]

44. Farrell, M.J. The measurement of productive efficiency. J. Royal Stat. Soc. Series A 1957, 120, $253-290$. [CrossRef]

45. Sueyoshi, T.; Goto, M. Methodological comparison between two unified (operational and environmental) efficiency measurements for environmental assessment. Eur. J. Oper. Res. 2011, 210, 684-693. [CrossRef]

46. Cooper, W.W.; Seiford, L.M.; Tone, K. Data Envelopment Analysis: A Comprehensive Text with Models, Applications, References and DEA-Solver Software, 2nd ed.; Springer: New York, NY, USA, 2007.

47. Porter, M.E. What is strategy? Harv. Bus. Rev. 1996, 74, 61.

48. Powell, T.C. Total quality management as competitive advantage: A review and empirical study. Strat. Manag. J. 1995, 16, 15-37. [CrossRef]

49. Kyrö, P. Revising the concept and forms of benchmarking. Benchmarking Int. J. 2003, 10, 210-225. [CrossRef]

50. Cook, W.D.; Tone, K.; Zhu, J. Data envelopment analysis: Prior to choosing a model. Omega 2014, 44, 1-4. [CrossRef]

51. Wang, S.; Zhou, L.; Wang, H.; Li, X. Water Use Efficiency and Its Influencing Factors in China: Based on the Data Envelopment Analysis (DEA)—Tobit Model. Water 2018, 10, 832. [CrossRef]

52. Novickytè, L.; Droždz, J. Measuring the Efficiency in the Lithuanian Banking Sector: The DEA Application. Int. J. Financ. Stud. 2018, 6, 37. [CrossRef]

53. Mazumder, S.; Kabir, G.; Hasin, M.A.A.; Ali, S.M. Productivity Benchmarking Using Analytic Network Process (ANP) and Data Envelopment Analysis (DEA). Big Data Cogn. Comput. 2018, 2, 27. [CrossRef]

54. Wang, C.-N.; Nguyen, V.T.; Duong, D.H.; Do, H.T. A Hybrid Fuzzy Analytic Network Process (FANP) and Data Envelopment Analysis (DEA) Approach for Supplier Evaluation and Selection in the Rice Supply Chain. Symmetry 2018, 10, 221. [CrossRef]

55. Lin, F.; Lin, S.-W.; Lu, W.-M. Sustainability Assessment of Taiwan's Semiconductor Industry: A New Hybrid Model Using Combined Analytic Hierarchy Process and Two-Stage Additive Network Data Envelopment Analysis. Sustainability 2018, 10, 4070. [CrossRef]

56. Wang, C.-N.; Tibo, H.; Duong, D.H. Renewable Energy Utilization Analysis of Highly and Newly Industrialized Countries Using an Undesirable Output Model. Energies 2020, 13, 2629. [CrossRef]

57. Emrouznejad, A.; Yang, G.-L. A framework for measuring global Malmquist-Luenberger productivity index with CO2 emissions on Chinese manufacturing industries. Energy 2016, 115, 840-856. [CrossRef]

58. Sözen, A.; Alp, I. Comparison of Turkey's performance of greenhouse gas emissions and local/regional pollutants with EU countries. Energy Policy 2009, 37, 5007-5018. [CrossRef]

59. Ren, C.; Li, R.H.; Guo, P. Two-Stage DEA Analysis of Water Resource Use Efficiency. Sustainability 2016, 9, 52. [CrossRef]

60. Mousavi-Avval, S.H.; Rafiee, S.; Jafari, A.; Mohammadi, A. Optimization of energy consumption for soybean production using Data Envelopment Analysis (DEA) approach. Appl. Energy 2011, 88, 3765-3772. [CrossRef]

61. Yu, Y.; Zhu, W.; Shi, Q.; Zhang, Q. Network-like DEA approach for environmental assessment: Evidence from U.S. manufacturing sectors. J. Clean. Prod. 2016, 139, 277-286. [CrossRef]

62. An, Q.; Pang, Z.; Chen, H.; Liang, L. Closest targets in environmental efficiency evaluation based on enhanced Russell measure. Ecol. Indic. 2015, 51, 59-66. [CrossRef] 
63. Önüt, S.; Soner, S. Energy efficiency assessment for the Antalya Region hotels in Turkey. Energy Build. 2006, 38, 964-971. [CrossRef]

64. Lozano, S.; Villa, G.; Brännlund, R. Centralised reallocation of emission permits using DEA. Eur. J. Oper. Res. 2009, 193, 752-760. [CrossRef]

65. Bevilacqua, M.; Braglia, M. Environmental efficiency analysis for ENI oil refineries. J. Clean. Prod. 2002, 10, 85-92. [CrossRef]

66. Färe, R.; Grosskopf, S.; Hernandez-Sancho, F. Environmental performance: An index number approach. Resour. Energy Econ. 2004, 26, 343-352. [CrossRef]

67. Simoes, P.; da Cruz, N.F.; Marques, R.C. The performance of private partners in the waste sector. J. Clean. Prod. 2012, 29, 214-221. [CrossRef]

68. Dyson, R.; Allen, R.; Camanho, A.; Podinovski, V.; Sarrico, C.; Shale, E. Pitfalls and protocols in DEA. Eur. J. Oper. Res. 2001, 132, 245-259. [CrossRef]

69. Asmild, M.; Paradi, J.C.; Aggarwall, V.; Schaffnit, C. Combining DEA Window Analysis with the Malmquist Index Approach in a Study of the Canadian Banking Industry. J. Prod. Anal. 2004, 21, 67-89. [CrossRef]

70. Yan, J.; Zhao, T.; Lin, T.; Li, Y. Investigating multi-regional cross-industrial linkage based on sustainability assessment and sensitivity analysis: A case of construction industry in China. J. Clean. Prod. 2017, 142, 2911-2924. [CrossRef]

71. Zhou, H.; Hu, H. Sustainability Evaluation of Railways in China Using a Two-Stage Network DEA Model with Undesirable Outputs and Shared Resources. Sustainability 2017, 9, 150. [CrossRef]

72. Oggioni, G.; Riccardi, R.; Toninelli, R. Eco-efficiency of the world cement industry: A data envelopment analysis. Energy Policy 2011, 39, 2842-2854. [CrossRef]

73. Li, L.-B.; Hu, J.-L. Ecological total-factor energy efficiency of regions in China. Energy Policy 2012, 46, $216-224$. [CrossRef]

74. Hua, Z.; Bian, Y.; Liang, L. Eco-efficiency analysis of paper mills along the Huai River: An extended DEA approach. Omega 2007, 35, 578-587. [CrossRef]

Publisher's Note: MDPI stays neutral with regard to jurisdictional claims in published maps and institutional affiliations.

(C) 2020 by the authors. Licensee MDPI, Basel, Switzerland. This article is an open access article distributed under the terms and conditions of the Creative Commons Attribution (CC BY) license (http://creativecommons.org/licenses/by/4.0/). 